\title{
SIMULAÇÃO DA VARIABILIDADE ESPACIAL DA EROSÃO HÍDRICA EM UMA SUB-BACIA HIDROGRÁFICA DE LATOSSOLOS NO SUL DE MINAS GERAIS ${ }^{(1)}$
}

\author{
Antônio Marciano da Silva ${ }^{(2)}$, Carlos Rogério de Mello ${ }^{(2)}$, Nilton \\ Curi $^{(3)} \&$ Polyanna Mara de Oliveira ${ }^{(4)}$
}

\begin{abstract}
RESUMO
A simulação da distribuição espacial da erosão do solo consiste em uma ferramenta poderosa para o planejamento conservacionista em bacias hidrográficas, sendo uma importante aplicação da Equação Universal de Perdas de Solo (EUPS) associada a princípios de interpolação espacial, principalmente a geoestatística. Este trabalho objetivou simular a distribuição espacial da erosão hídrica numa sub-bacia hidrográfica da região do Alto Rio Grande (MG), aplicando ferramentas geoestatísticas para distribuição espacial e mapeamento. Diferentes cenários de uso do solo foram analisados. A erosão foi estimada com base na EUPS aplicada a células, considerando as unidades pedológicas e diferentes usos em cada célula. $O$ fator topográfico (LS) das células foi obtido com base no Modelo Digital de Elevação da sub-bacia, identificando comprimento e direção principal do escoamento. A erosividade média anual da região é de $8.030 \mathrm{MJ} \mathrm{mm} \mathrm{ha-1} \mathrm{h}^{-1}$ ano $^{-1}$, e a erodibilidade dos solos foi extraída da literatura. A EUPS foi aplicada a cada célula, levando-se em conta a situação atual do solo, áreas degradadas plantadas com eucalipto, pastagem plantada e plantio convencional de milho, considerando a ocupação de toda a sub-bacia hidrográfica. Na situação atual, a sub-bacia apresenta taxas de erosão inferiores aos limites de tolerância para os respectivos solos, com exceção das áreas degradadas ocupadas por eucalipto e pastagem em Cambissolo. No entanto, em todas as situações analisadas, seu lado leste apresentou as maiores perdas de solo, especialmente para os cenários de eucalipto nas condições atuais e plantio convencional de milho em Cambissolo e Latossolo Vermelho-Amarelo, sendo necessária a aplicação de técnicas conservacionistas.
\end{abstract}

Termos de indexação: geoestatística, manejo ambiental, mapeamento, EUPS.

\footnotetext{
(1) Recebido para publicação em outubro de 2007 e aprovado em julho de 2008.

(2) Professor do Departamento de Engenharia da Universidade Federal de Lavras - UFLA. Caixa Postal 3037, CEP 37200-000 Lavras (MG) Pesquisadores Bolsistas do CNPq. E-mails: marciano@ufla.br; crmello@ufla.br

(3) Professor do Departamento de Ciência do Solo, UFLA. Pesquisador Bolsista do CNPq. E-mail: niltcuri@ufla.br

${ }^{(4)}$ Pesquisadora Bolsista do Programa Embrapa/Café, DEG/UFLA. E-mail: polyanna.oliveira@uol.com.br
} 


\title{
SUMMARY: SIMULATION OF WATER EROSION SPATIAL VARIABILITY IN A WATERSHED REPRESENTATIVE OF OXISOLS IN SOUTHERN MINAS GERAIS STATE
}

\begin{abstract}
Simulation of water erosion spatial distribution is an important tool for soil conservation planning in watersheds, being an important application of the Universal Soil Loss Equation (USLE) using interpolation principles, such as geostatistics. This study aimed to simulate spatial distribution of water erosion in a watershed of the Alto Rio Grande $(M G)$ region, applying geostatistical tools for mapping, considering different land use scenarios. Water erosion was estimated by the USLE applied to grid cells, weighing. pedologic units and land use distribution in each cell. The topographical factor $(L S)$ of the cells was obtained based on a Digital Elevation Model of the sub-watershed, identifying length and main flow direction. Mean annual rainfall erosivity in the region is 8,030 $\mathrm{MJ} \mathrm{mm} \mathrm{ha-1} \mathrm{h}^{-1}$ year-1 and the underlying soil erodibility values were based on data from the literature. Mapping was carried out considering the current land uses in the entire watershed, where eucalyptus was grown on degraded soils, grasses planted as pasture and corn tilled conventionally. Under the current land uses, soil losses from the watershed were not relevant, except in areas covered with eucalyptus and grass on Cambisol (Inceptisol). In all simulations, the highest soil losses were verified on the eastern side of the watershed, especially for eucalyptus and conventional corn on Cambisol and Dystrophic Red-Yellow Latosol (Oxisol), where special soil conservation techniques are needed.
\end{abstract}

Index terms: geostatistics, environmental management, mapping, USLE.

\section{INTRODUÇÃO}

A erosão do solo e a degradação de terras agricultáveis são dos mais significativos problemas ambientais da atualidade. A intervenção eficiente no controle da erosão em bacias rurais requer a aplicação de modelos capazes de estimar satisfatoriamente a produção dos sedimentos. Nesse sentido, existem diversos modelos de predição da erosão com variados graus de complexidade. O modelo mais simples consiste na Equação Universal de Perdas de Solo (EUPS), a qual estima as perdas anuais de solo com boa acurácia nas condições brasileiras. A EUPS expressa a perda de solo por unidade de área e considera fatores como erosividade da chuva, erodibilidade do solo, topografia, uso e manejo do solo e práticas conservacionistas (Wishmeyer \& Smith, 1978).

$\mathrm{O}$ uso de modelos distribuídos no espaço consiste de uma poderosa ferramenta para análise ambiental em escala de bacias hidrográficas, destacando-se a erosão hídrica dos solos. Pesquisas têm mostrado que o SIG (Sistema de Informações Geográficas) pode ser efetivamente usado para investigar regiões vulneráveis quanto à erosão e estimar a produção de sedimentos de acordo com o uso do solo (Irven et al., 2007; Pandey et al., 2007). Entretanto, resultados positivos e aplicáveis somente serão alcançados se dados básicos, como pedológicos, de uso do solo, relevo e topografia, entre outros, forem adequadamente mapeados para posterior aplicação.

Geralmente, os modelos de predição de erosão associados ao SIG são complexos e requerem grande número de variáveis de entrada (Pandey et al., 2007).
Entretanto, alguns autores, como Irven et al. (2007), Onyando et al. (2005) e Fistikoglu \& Harmanciogu (2002) aplicaram a EUPS juntamente com o SIG e uma ferramenta de interpolação linear, normalmente o inverso da distância, e concluíram que seu uso propiciou maior eficiência e acurácia na aplicação da EUPS para bacias hidrográficas rurais. No entanto, Wang et al. (2003) e Pérez-Rodriguez et al. (2007) aplicaram a geoestatística para o mapeamento da erodibilidade e da erosão em áreas agrícolas, encontrando resultados promissores e mais exatos do comportamento da erosão com aplicação desta técnica.

A geoestatística consiste em uma ferramenta de mapeamento e simulação de variáveis contínuas no espaço que pode ser acoplada ao SIG, visando produzir informações ambientais de cunho prático e, principalmente, sem tendenciosidade (Mello, 2004; Diggle \& Ribeiro Júnior, 2007). Como a erosão hídrica é caracterizada e modelada por atributos de solo com comportamento contínuo no espaço, incluindo cobertura vegetal, topografia e erosividade da chuva, todas contínuas e com estrutura de continuidade espacial (Becerra-Soriano \& Gutiérrez-López, 2006; Mello et al., 2007), esta poderá ser mapeada por um modelo espacial típico da geoestatística, desde que estudos sobre sua estrutura de dependência espacial sejam adequadamente desenvolvidos, sobretudo na modelagem do semivariograma experimental.

Nesse contexto, objetivou-se, com este trabalho, simular e mapear a erosão hídrica produzida em uma sub-bacia hidrográfica tipicamente agrícola, considerando diferentes cenários de ocupação e uso do solo, por meio da geoestatística, identificando zonas de maior sensibilidade à erosão em relação ao uso do solo. 
MATERIAL E MÉTODOS

\section{Caracterização da sub-bacia hidrográfica do Ribeirão Marcela e parcelas de perda de solo}

A sub-bacia hidrográfica do Ribeirão Marcela é afluente pela margem direita do córrego Jaguara, que deságua diretamente no reservatório da UHE de Camargos/CEMIG. Situa-se entre as coordenadas UTM 550169 e 552810 de longitude W e 7650163 e 7650989 de latitude S, fuso $23 \mathrm{k}$, e entre as altitudes de 960 e $1.060 \mathrm{~m}$. Está inserida na unidade geomorfológica Planalto Campos das Vertentes, na região Alto Rio Grande, Sul de Minas Gerais (Figura 1).

A sub-bacia hidrográfica possui área de drenagem de 478 ha, declividade média de 13,65 \% e elevação média de $1.003 \mathrm{~m}$. Há predominância do Latossolo Vermelho-Amarelo (LVAd), ocupando aproximadamente $65 \%$ da área; o Latossolo Vermelho (LVd) ocupa cerca de $14 \%$; os Cambissolos Háplicos (CXbd), 6 \% da área; e os Gleissolos (GX), 15 \% (Figura 2a). Com base em estudos pedológicos e hidrológicos, essa sub-bacia foi escolhida como representativa dos Latossolos na região do Alto Rio Grande a montante da UHE de Camargos/ CEMIG (Araújo, 2006).

Na área da sub-bacia hidrográfica há predominância de propriedades rurais voltadas para produção leiteira, razão pela qual se destacam a pastagem, em 75,87 \% da área, e de forma menos expressiva, pequenas lavouras de subsistência de milho, arroz e canade-açúcar, além de fragmentos de mata nativa, áreas degradadas plantadas com eucalipto e áreas cultivadas com maracujá (Figura $2 b$ )
Foram instaladas quatro parcelas de perda de solo (Figura 2 b) para avaliação do fator de cobertura C, buscando-se representatividade tanto das unidades pedológicas quanto de uso do solo na sub-bacia hidrográfica, seguindo-se o padrão proposto por Wischmeier \& Smith (1978), com comprimento de rampa de $10 \mathrm{~m}$; na parte inferior foram instaladas calhas coletoras, que conduzem a enxurrada para dois tanques de $250 \mathrm{~L}$ cada, interligados por divisor tipo Geib com 11 janelas. As condições e o tipo de solo em cada parcela são os seguintes:

Parcela 1: Latossolo Vermelho-Amarelo distrófico típico em plantio degradado de eucalipto, com declividade de $10 \%$

Parcela 2: Latossolo Vermelho-Amarelo distrófico típico em pastagem plantada e $15 \%$ de declive.

Parcela 3: Cambissolo Háplico distrófico típico em pastagem nativa e declividade de $15 \%$.

Parcela 4: Latossolo Vermelho distrófico típico em pastagem nativa, com declividade de $10 \%$.

O período de monitoramento foi de dezembro de 2004 a junho de 2006. Além disso, uma estação meteorológica completa, que fornece parâmetros climáticos a cada 15 min, está instalada na sub-bacia desde 2004. As demais características fisiográficas básicas das parcelas encontram-se no quadro 1 .

\section{Simulação da erosão na sub-bacia hidrográfica do Ribeirão Marcela}

A primeira etapa de levantamento de dados para simulação consistiu na caracterização do fator de cobertura $\mathrm{C}$, com base na análise dos dados de

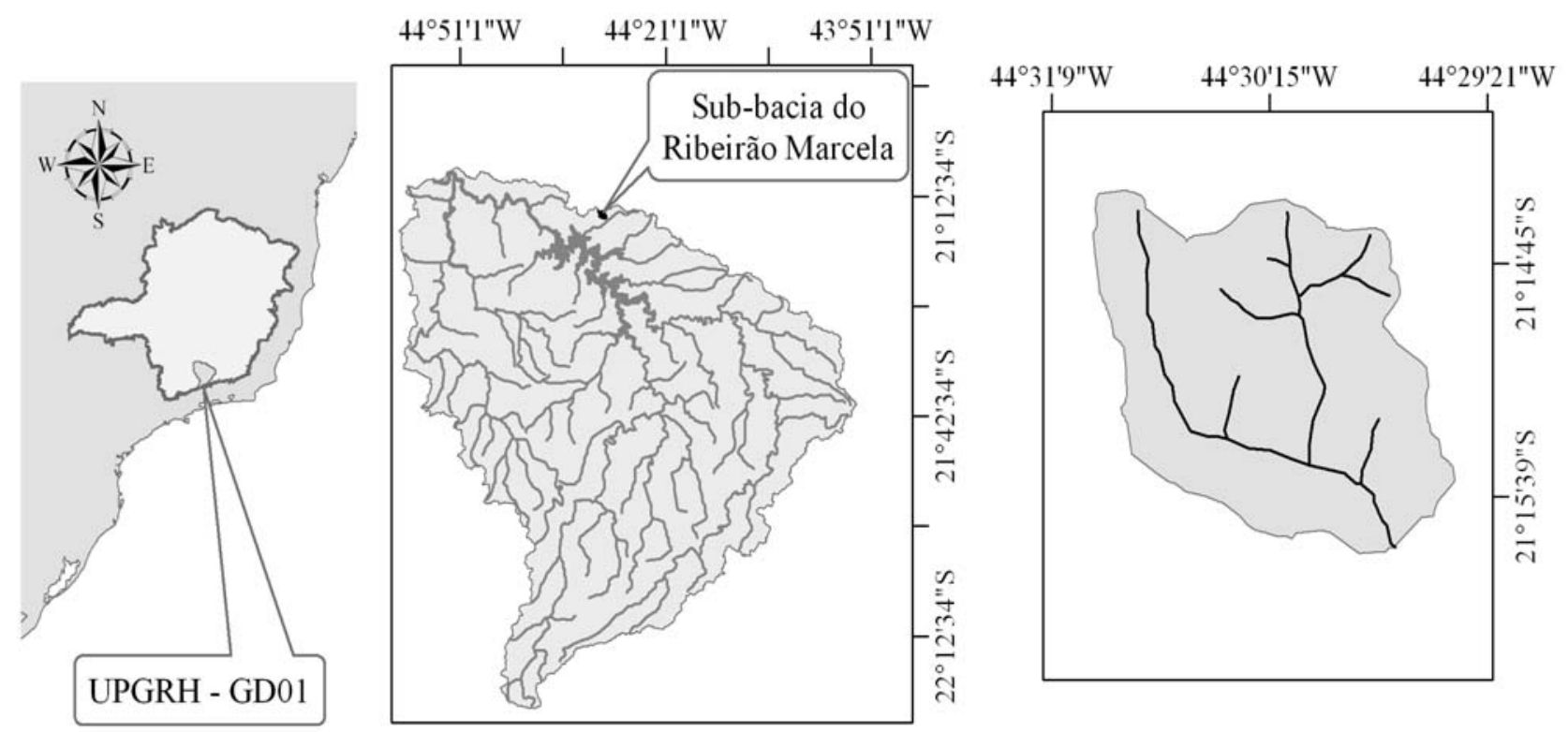

Figura 1. Localização da sub-bacia hidrográfica do Ribeirão Marcela em Minas Gerais e sua inserção na Unidade de Planejamento e Gestão dos Recursos Hídricos (UPGRH - GD01). 

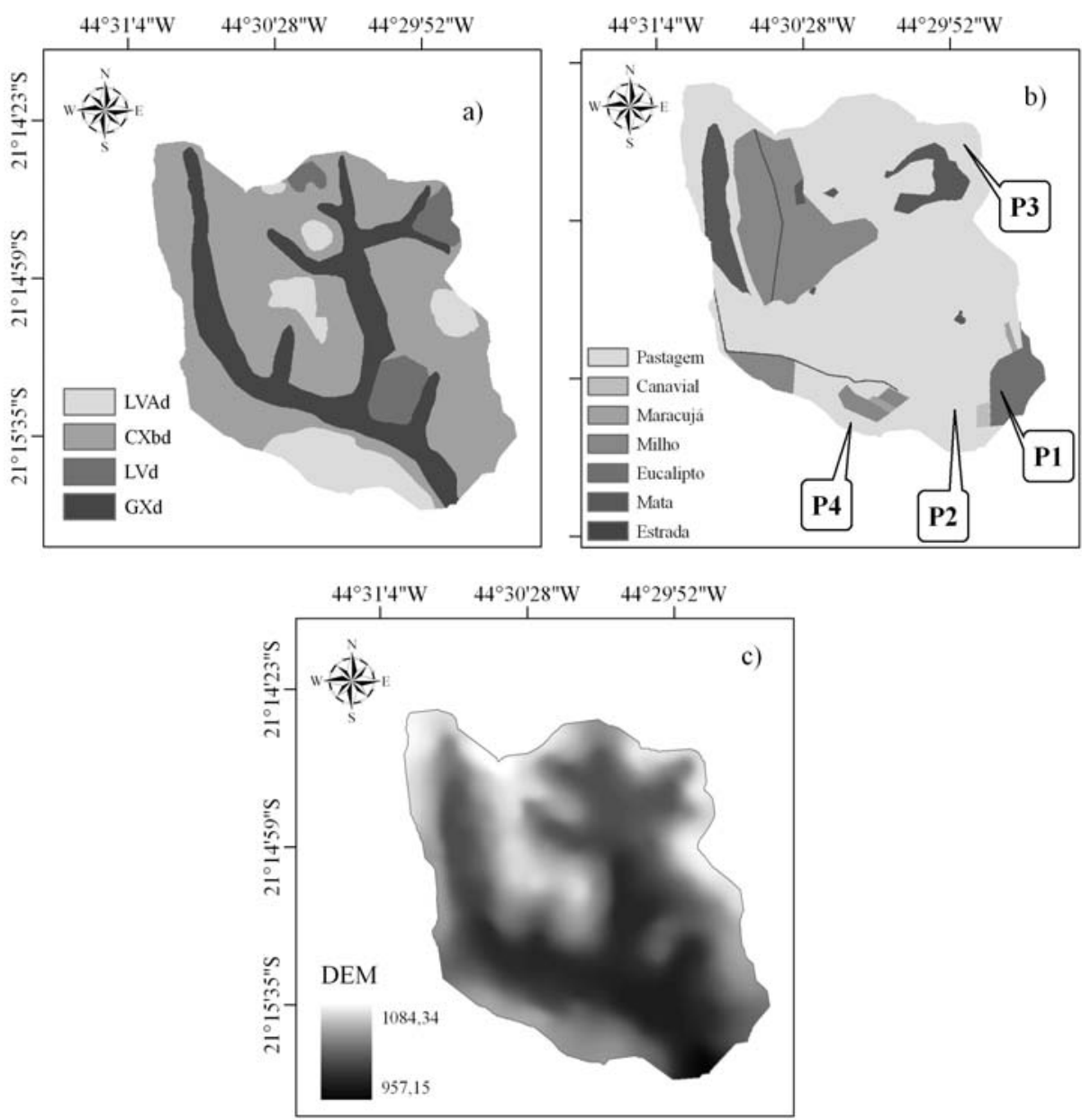

Figura 2. Unidades pedológicas da sub-bacia hidrográfica do Ribeirão Marcela (a), mapa de uso do solo com localização das parcelas de perda de solo (b) e modelo digital de elevação (c).

Quadro 1. Características fisiográficas e atributos físicos dos solos das parcelas de perda de solo instaladas na sub-bacia hidrográfica do Ribeirão Marcela

\begin{tabular}{|c|c|c|c|c|c|c|c|c|c|}
\hline Parcela & Solo & $\mathbf{A}$ & I & Uso & $\rho s$ & MO & $\mathbf{k}_{\mathrm{o}}$ & VTP & ADA \\
\hline & & $\mathrm{m}^{2}$ & $\%$ & & $\mathrm{Mg} \mathrm{m}^{-3}$ & $\mathrm{~g} \mathrm{~kg}^{-1}$ & $\mathrm{~m} \operatorname{dia}^{-1}$ & $\mathrm{~m}^{3} \mathrm{~m}^{-3}$ & $\%$ \\
\hline 1 & LVA & 30,0 & 10 & 1 & 1,127 & 37,90 & 0,955 & 0,552 & 9,91 \\
\hline 2 & LVA & 30,3 & 15 & 2 & 1,127 & 37,90 & 0,955 & 0,552 & 9,91 \\
\hline 3 & $\mathrm{CX}$ & 29,9 & 15 & 3 & 1,168 & 33,25 & 0,612 & 0,552 & 12,3 \\
\hline 3 & LV & 26,4 & 10 & 2 & 1,056 & 35,33 & 1,153 & 0,589 & 6,81 \\
\hline
\end{tabular}

Uso 1: Plantação de eucalipto em área degradada, com exposição do solo; Uso 2: Pastagem plantada (braquiária); Uso 3: Pastagem nativa. rs: densidade do solo; MO: matéria orgânica; $\mathrm{k}_{0}$ : condutividade hidráulica saturada; VTP: volume total de poros; ADA: argila dispersa em água; A: área da parcela; I: declividade da parcela.

monitoramento das parcelas de perda de solo, uma vez que há grande incerteza associada a esse fator. Para isso, a EUPS foi aplicada da seguinte forma, seguindo método aplicado por Prochnow et al. (2005):

$$
\mathrm{C}=\frac{\mathrm{A}}{\mathrm{R} \times \mathrm{K} \times \mathrm{LS} \times \mathrm{P}}
$$

em que $\mathrm{C}$ é o fator de cobertura médio no período de

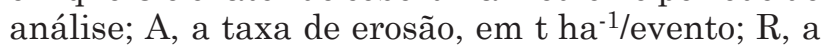
erosividade da respectiva chuva, em MJ mm ha ${ }^{-1} \mathrm{~h}^{-1} /$

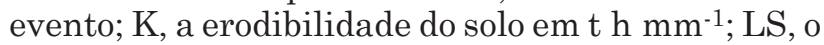
fator topográfico (comprimento de rampa e declividade); e $\mathrm{P}$ representa as práticas culturais, considerado igual a $1 \mathrm{em}$ todas as parcelas. Para a 
erodibilidade, trabalhou-se com os valores de 0,010 t $\mathrm{h} \mathrm{mm}^{-1}$ para o LVAd (Silva, 1997), 0,004 $\mathrm{t} \mathrm{h} \mathrm{m} \mathrm{m}^{-1}$ para o LVd (Silva, 1997) e 0,024 $\mathrm{t} \mathrm{h} \mathrm{mm}^{-1}$ para o Cambissolo (CXbd) (Silva et al., 2005), uma vez que esses valores são consagrados e aceitos pela literatura científica. Ao se analisar o uso atual do solo na sub-bacia hidrográfica, percebe-se que algumas situações não foram cobertas pelo monitoramento das parcelas. Essas situações foram estimadas com base nos valores de $\mathrm{C}$ levantados, tendose como referência a erodibilidade dos solos, ou seja, espera-se que para uma mesma cobertura vegetal haja maior taxa de erosão no Cambissolo, seguida pelo LVAd e, por último, pelo LV, com base em estudos anteriores (Lima et al., 1990; Silva et al., 2005). Com base nesse critério, no quadro 2 apresentam-se os valores médios de $\mathrm{C}$ para cada uso e unidade pedológica adotados na simulação. $\mathrm{O}$ fator $\mathrm{P}$ para milho convencional foi de 0,5 ; os demais, iguais a 1 .

A sub-bacia hidrográfica foi dividida em células de $200 \times 200$ m, de acordo com Pandey et al. (2007), incluindo os solos que compõem cada célula, bem como seus diferentes usos. O fator C médio para cada célula foi obtido, primeiramente, para cada unidade pedológica a partir da ponderação pelo respectivo uso e, em seguida, ponderando-se pelos percentuais de ocupação de cada solo. Matematicamente, tem-se:

$$
\overline{\mathrm{C}}_{\text {solo }}=\frac{\sum_{\mathrm{i}=1}^{\mathrm{n}} \mathrm{P}_{\mathrm{i}} \times \mathrm{C}_{\text {solo }}-\text { uso }}{\sum_{\mathrm{i}=1}^{\mathrm{n}} \mathrm{P}_{\mathrm{i}}}
$$

em que $\mathrm{P}_{\mathrm{i}}$ representa o respectivo uso do solo; $\mathrm{C}_{\text {solo-uso, }}$ fator de cobertura da situação solo x uso; e (n), os diferentes usos do respectivo solo. $\mathrm{O}$ fator $\mathrm{C}$ final nas células foi obtido por:

$$
\overline{\mathrm{C}}_{\text {célula }}=\frac{\sum_{\mathrm{j}=1}^{\mathrm{n}} \mathrm{P}_{\mathrm{j}} \times \overline{\mathrm{C}}_{\text {solo }}}{\sum_{\mathrm{j}=1}^{\mathrm{n}} \mathrm{P}_{\mathrm{j}}}
$$

em que $\mathrm{P}_{\mathrm{j}}$ é o peso de cada solo dentro das células e $\mathrm{m}$ o número de unidades pedológicas dentro de cada

Quadro 2. Fatores C da EUPS utilizados na simulação da erosão na sub-bacia hidrográfica do Ribeirão Marcela

\begin{tabular}{lccc}
\hline \multicolumn{1}{c}{ Uso do solo } & LVA & LV & CX \\
\hline Mata & 0,001 & 0,001 & 0,001 \\
Eucalipto em área degradada & 0,162 & 0,147 & 0,180 \\
Milho & 0,150 & 0,140 & 0,200 \\
Cana & 0,120 & 0,109 & $*$ \\
Pastagem & 0,032 & 0,029 & 0,048 \\
Maracujá & 0,150 & $*$ & $*$ \\
\hline
\end{tabular}

* Sem combinação na sub-bacia e situação não presente na simulação. célula. O fator topográfico LS de cada célula foi avaliado com base no modelo digital de elevação da sub-bacia, detectando-se o comprimento e a direção principal do escoamento na célula (Figura 2b,c), subdividindo-o em partes com no máximo $40 \mathrm{~m}$ cada, calculando sua declividade trecho a trecho e obtendo o fator LS médio final ponderado pelo respectivo comprimento de rampa, conforme Ranieri et al. (2002) e Fistikoglu \& Harmanciogu (2002):

$$
\mathrm{LS}_{\text {célula }}=\frac{\sum_{\mathrm{i}=1}^{\mathrm{S}} \mathrm{LS}_{\mathrm{i}} \times 1_{\mathrm{i}}}{\sum_{\mathrm{i}=1}^{\mathrm{S}} 1_{\mathrm{i}}}
$$

em que $\mathrm{l}_{\mathrm{i}}$ é o comprimento do trecho; $\mathrm{LS}_{\mathrm{i}}$, o fator $\mathrm{LS}$ do respectivo trecho; e $\mathrm{LS}_{\text {célula }}$, o fator topográfico de cada célula. Cada um dos fatores $\mathrm{LS}_{\mathrm{i}}$ foi corrigido da seguinte forma (Wischmeier \& Smith, 1978):

$$
\mathrm{LS}_{\mathrm{i}}=\left(\frac{1_{\mathrm{i}}}{22,1}\right)^{\mathrm{m}} \times\left(0,065+0,0454 \mathrm{~S}+0,0065 \mathrm{~S}^{2}\right)
$$

sendo $\mathrm{m}=0,2$ para $\mathrm{S}<1 \%, \mathrm{~m}=0,3$ para $1 \% \leq \mathrm{S} \leq$ $3 \% ; \mathrm{m}=0,4$ e $3 \% \leq \mathrm{S} \leq 5 \% ; \mathrm{m}=0,5$ para $\mathrm{S}>5 \%$.

A erodibilidade em cada célula foi estimada pela ponderação do respectivo solo, considerando-se as partes da célula com o Gleissolo com erodibilidade nula, visto que são áreas caracterizadas como de deposição (receptoras).

$$
\overline{\mathrm{K}}_{\text {célula }}=\frac{\sum_{\mathrm{i}=1}^{\mathrm{t}} \mathrm{P}_{\mathrm{i}} \times \mathrm{K}_{\text {soloi }}}{\sum_{\mathrm{i}=1}^{\mathrm{t}} \mathrm{P}_{\mathrm{i}}}
$$

em que Pi refere-se à percentagem de ocupação da célula pelo respectivo solo; $\mathrm{K}_{\text {soloi }}$, à erodibilidade do respectivo solo; e t ao número de unidades pedológicas.

As estimativas de erosão em cada célula foram obtidas considerando uma erosividade anual média (R) para a região de $8.030 \mathrm{MJ} \mathrm{mm} \mathrm{ha}^{-1} \mathrm{~h}^{-1}$ ano $^{-1}$ (Mello et al., 2007). Assim, a EUPS foi aplicada a cada célula, estimando-se a respectiva taxa de erosão em t ha-1 ano $^{-1}$, considerando a situação atual de uso do solo (Figura 2c) e estruturando um banco de dados georreferenciados. Os demais cenários seguiram as tendências atuais de uso do solo na sub-bacia, ou seja, ocupação total desta por eucalipto basicamente para madeira e com grande espaçamento (áreas degradadas), ocupação total do solo por pastagem plantada e ocupação por milho com plantio convencional.

\section{Mapeamento da erosão na sub-bacia hidrográfica do Ribeirão Marcela}

O mapeamento da erosão foi desenvolvido com aplicação da geoestatística baseada em modelo (Diggle \& Ribeiro Júnior, 2007), considerando-se como 
amostras os valores estimados de erosão anual em cada célula. $\mathrm{O}$ interpolador geoestatístico (krigagem) vem sendo aplicado com sucesso para mapear atributos de solo, em especial sua erodibilidade (Pérez-Rodriguez et al., 2007) e outros fatores associados à erosão, entre eles a própria taxa de erosão, conforme Wang et al. (2003), os quais aplicaram a geoestatística associada a um SIG para mapeamento da erosão propriamente dita. Ambos os autores mencionam que a krigagem geoestatística pode desenvolver papel importante no processo de mapeamento de variáveis contínuas, como os atributos físicos e químicos do solo, e é reconhecida como um "interpolador ótimo", devido às suas propriedades de interpolação não-enviesada (sem tendência) e variância mínima das estimativas, sendo estas características estatísticas altamente desejáveis em interpoladores espaciais (Isaak \& Srivastava, 1989).

O georreferenciamento dos dados foi feito levandose em conta o centro geométrico da respectiva célula. A primeira etapa deste estudo foi promover uma análise exploratória dos dados, especialmente avaliandose o comportamento do histograma das diferenças entre pares de pontos no espaço, o qual deve produzir normalidade. Essa análise é importante em função do método de ajuste adotado dos semivariogramas, que é o da Máxima Verossimilhança, pois seu algoritmo assume normalidade bivariada, conforme Diggle \& Ribeiro Júnior (2007) e Mello (2004). A adoção desse método deve-se ao fato de que é possível obter diretamente a média espacial, a qual é mais exata do que a aritmética, quando os dados apresentam estrutura de continuidade espacial (Mello, 2004). Os modelos de semivariograma exponencial e esférico foram ajustados e testados. A estruturação matemática e respectivos comportamentos podem ser encontrados em Mello (2004) e Isaaks \& Srivastava (1989), entre outros.

Para avaliação do melhor modelo a ser aplicado no mapeamento pela krigagem, trabalhou-se com a validação cruzada, obtendo-se, por meio desta, o Quadrado Médio do Erro (Mello, 2004; Diggle \& Ribeiro
Júnior, 2007). Os demais critérios foram o Grau de Dependência Espacial - GD (Cambardella et al., 1994; Mello, 2004) e o Critério de Akaike - AIC (Mello, 2004; Diggle \& Ribeiro Júnior, 2007). As expressões para o cálculo do grau de dependência espacial (GD) e AIC, respectivamente, são:

$$
\mathrm{GD}=\left(\frac{\mathrm{C}_{1}}{\mathrm{C}_{1} \times \mathrm{C}_{0}}\right) \times 100
$$

em que $\mathrm{C}_{1}$ corresponde ao patamar do semivariograma, refletindo o "tamanho estatístico" da continuidade espacial, e $\mathrm{C}_{0}$ é o efeito pepita, consistindo na descontinuidade espacial dos dados, ou seja, parcela do erro que não é possível controlar ("ruído"); e

$$
\mathrm{AIC}=-2 \times \mathrm{M}(\log \mathrm{MV})
$$

em que $\mathrm{M}(\log \mathrm{MV})$ diz respeito ao valor máximo do logaritmo da máxima verossimilhança. Quanto menor o AIC, maior a exatidão do ajuste, e, se a diferença entre os valores AIC dos modelos for menor que 2, não há diferença estatística entre estes (Diggle \& Ribeiro Júnior, 2007). Todas as análises geoestatísticas foram desenvolvidas com o programa $\mathrm{R}$, no pacote GeoR, seguindo instruções de Ribeiro Júnior \& Diggle (2001) e Mello (2004). Com base neste estudo, o mapeamento propriamente dito foi desenvolvido com o programa ArcMap, em ambiente SIG.

\section{RESULTADOS E DISCUSSÃO}

\section{Continuidade espacial da erosão na sub- bacia hidrográfica do Ribeirão Marcela}

A modelagem do semivariograma, bem como os parâmetros que expressam a qualidade estatística de seu ajuste, subsidiando a determinação do melhor modelo, estão apresentados no quadro 3. Segundo Mello (2004) e Ribeiro Júnior \& Diggle (2001), essas análises são fundamentais para geração de mapas sem

Quadro 3. Parâmetros de ajuste e de exatidão dos modelos de semivariograma ajustados por Máxima

\begin{tabular}{|c|c|c|c|c|c|c|}
\hline Modelo & $\mathbf{C}_{\mathbf{o}}$ & $\mathbf{C}_{1}-\mathbf{C}_{\mathrm{o}}$ & Ac & QME & GD & AIC \\
\hline & & & $\mathrm{m}$ & & $\%$ & \\
\hline $\begin{array}{l}\text { Exponencial } \\
\text { Esférico }\end{array}$ & $\begin{array}{l}0,0 \\
0,0\end{array}$ & $\begin{array}{l}0,0682 \\
0,0616\end{array}$ & $\begin{array}{l}721,92 \\
473,05\end{array}$ & $\begin{array}{l}0,042 \\
0,038\end{array}$ & $\begin{array}{l}100 \\
100\end{array}$ & $\begin{array}{r}9,06 \\
14,02\end{array}$ \\
\hline $\begin{array}{l}\text { Exponencial } \\
\text { Esférico }\end{array}$ & $\begin{array}{l}0,0 \\
0,252\end{array}$ & $\begin{array}{l}0,4147 \\
0,1801\end{array}$ & $\begin{array}{l}450,09 \\
818,56\end{array}$ & $\begin{array}{l}0,353 \\
0,357\end{array}$ & $\begin{array}{l}100 \\
63,17\end{array}$ & $\begin{array}{l}168,8 \\
169,4\end{array}$ \\
\hline $\begin{array}{l}\text { Exponencial } \\
\text { Esférico }\end{array}$ & $\begin{array}{l}0,0 \\
0,0152\end{array}$ & $\begin{array}{l}0,0252 \\
0,0111\end{array}$ & $\begin{array}{l}433,17 \\
786,91\end{array}$ & $\begin{array}{l}0,0218 \\
0,0219\end{array}$ & $\begin{array}{l}100 \\
63,37\end{array}$ & $\begin{array}{l}82,54 \\
83,16\end{array}$ \\
\hline $\begin{array}{l}\text { Exponencial } \\
\text { Esférico }\end{array}$ & $\begin{array}{l}0,0 \\
0,0725\end{array}$ & $\begin{array}{l}0,1125 \\
0,0440\end{array}$ & $\begin{array}{l}412,38 \\
783,44\end{array}$ & $\begin{array}{l}0,0992 \\
0,1005\end{array}$ & $\begin{array}{l}100 \\
61,64\end{array}$ & $\begin{array}{l}53,12 \\
55,76\end{array}$ \\
\hline
\end{tabular}
Verossimilhança

Co: efeito pepita; C1-Co: contribuição (patamar - efeito pepita); Ac: alcance; QME: quadrado médio do erro; GD: grau de dependência; AIC: estatística do teste de Akaike. 
tendenciosidade e não-enviesados, algo que a krigagem geoestatística, partindo de uma boa modelagem do semivariograma, produz, gerando informações espacializadas de forma mais consistente que os demais interpoladores tradicionalmente aplicados ao SIG (Mello et al., 2003).

Quanto à situação de uso atual do solo na subbacia hidrográfica, é possível observar que os modelos esférico e exponencial apresentam ajustes muito próximos, com o QME e o GD praticamente iguais, sendo o primeiro parâmetro ligeiramente menor para o modelo esférico. No entanto, os valores de AIC apontam para melhor ajuste do modelo exponencial, devido ao seu menor valor. Além disso, a diferença supera o mínimo necessário para caracterizar uma diferença significativa, mostrando que, estatisticamente, há divergência entre os modelos. Para o uso do solo essencialmente com eucalipto, o melhor modelo foi definido pelo elevado grau de dependência, apesar de o QME e o AIC não diferirem. Análise semelhante foi obtida para as situações de pastagem e milho, ou seja, pequenas diferenças nos parâmetros estatísticos de ajuste, mas com grau de dependência consideravelmente superior e diferença maior que 2 no AIC, indicando que o modelo exponencial deve ser aplicado ao processo de mapeamento pela krigagem em todos os cenários estruturados. Souza et al. (2005), estudando a variabilidade espacial do risco à erosão para um Latossolo Vermelho eutroférrico de uma área do nordeste do Estado de São Paulo, encontraram no modelo exponencial melhor ajuste do semivariograma, obtendo efeito pepita consideravelmente baixo, semelhante ao ajustado por este trabalho.

\section{Distribuição espacial da erosão na sub-bacia hidrográfica}

Das situações simuladas, a ocupação dos solos por plantios de eucalipto em áreas degradadas, com elevada exposição do solo, semelhante às condições atuais, é a que apresenta a situação mais crítica de erosão, atingindo valores superiores a $3,5 \mathrm{t} \mathrm{ha}^{-1} \mathrm{ano}^{-1}$ (Quadro 4). Em contrapartida, se a sub-bacia fosse inteiramente ocupada por pastagem plantada, haveria tendência de ocorrer os menores valores de perda de solo, tanto em termos médios quanto de valor máximo. Tomando como referência os limites de tolerância para Latossolos da ordem de 10-12 t ha-1 ano-1 (Silva et al.,
2005; Sparovek \& Jong van Lier, 1997) e para os Cambissolos da região de $2 \mathrm{t} \mathrm{ha}^{-1}$ ano $^{-1}$ (Silva et al., 2005), verifica-se que, na situação atual, a sub-bacia não apresenta elevado estádio de degradação do solo, visto que as taxas de erosão foram inferiores aos limites de tolerância. No entanto, quando se introduziu milho com plantio convencional ou eucalipto como uso predominante na sub-bacia, foi possível identificar locais com alta taxa de erosão principalmente no Cambissolo e em alguns trechos de LVAd, indicando setores na sub-bacia que podem atingir elevado grau de degradação. Essa situação merece atenção especial devido à constatação de sérios problemas associados ao voçorocamento na região do Alto Rio Grande, havendo um modelo geral que está associado à erosão acelerada no Cambissolo e sua extensão para os Latossolos, sobretudo os de cor mais amarelada, no terço superior da encosta (Silva, 1990).

Analisando o desvio-padrão dos valores (Quadro 4), verifica-se que para uso do solo associado ao eucalipto e milho, a taxa de erosão pode superar o limite de tolerância para o Cambissolo, mostrando que, nessas condições, são necessárias ações conservacionistas para minimização dos prováveis impactos ambientais.

Observam-se quatro regiões com considerável processo erosivo, coincidindo com os Cambissolos e uso do solo com eucalipto e milho (Figura 3). Especialmente na ocupação com eucalipto, observam-se as maiores taxas de erosão, aproximando-se de 1,5 $\mathrm{t} \mathrm{ha}^{-1} \mathrm{ano}^{-1}$, valor inferior ao limite de tolerância de perdas dos solos da sub-bacia hidrográfica.

Verifica-se para o eucalipto em áreas degradadas aumento de áreas com taxas de erosão mais elevadas, próximas de $4 \mathrm{t} \mathrm{ha}^{-1}$ ano $^{-1}$ (Figura 3). A combinação de Cambissolo com plantio de eucalipto em áreas degradadas consiste na situação mais crítica de erosão para o manejo da sub-bacia, produzindo valores consideravelmente superiores ao de tolerância de perdas desse solo. É importante mencionar que há formação de uma faixa de erosão crítica no lado leste da sub-bacia, com picos visíveis no mapa, sendo essencial implantar práticas conservacionistas nesse setor da sub-bacia. Uma das explicações para essa situação está associada ao comportamento mais acidentado do relevo nesse setor, com produção de fatores LS sensivelmente mais elevados (Figura 2b,c).

Quadro 4. Estatísticas gerais do comportamento da erosão na sub-bacia hidrográfica do Ribeirão Marcela

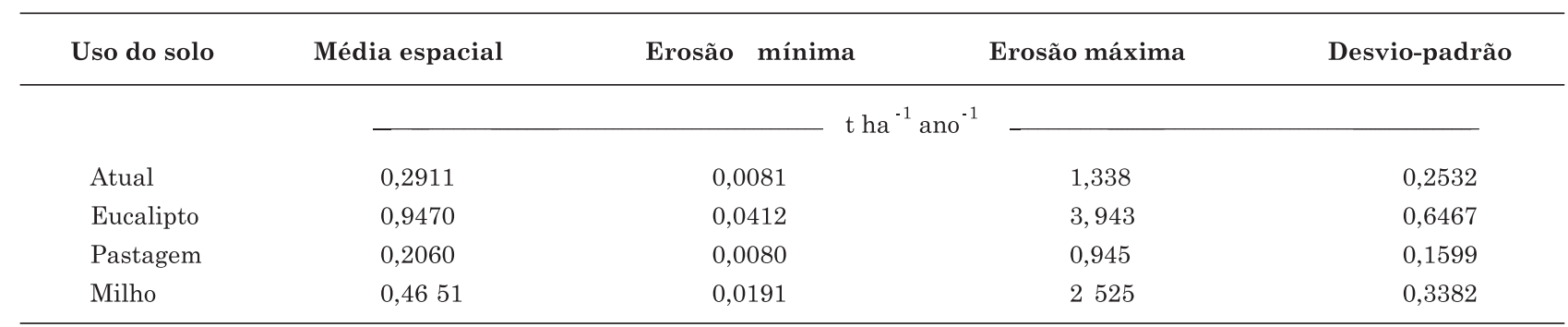


O mapa de erosão simulado para uso do solo na sub-bacia hidrográfica com pastagem plantada está representado na figura 3c. Verifica-se redução expressiva de áreas da sub-bacia hidrográfica com taxas de erosão mais altas, em relação aos cenários da figura 3a,b. As maiores taxas de erosão foram simuladas para o Cambissolo com pastagem, sendo, contudo, inferiores ao limite de tolerância de perdas $\left(<2,0 \mathrm{t} \mathrm{ha}^{-1}\right.$ ano $\left.^{-1}\right)$. O efeito da pastagem na proteção do solo contra a erosão é conhecido, estando normalmente associado à maior estabilidade de agregados em água, além da maior agregação do solo, pela maior concentração de matéria orgânica nestas áreas (Quadro 1). Contudo, o uso do solo como pastagem de forma constante pode produzir redução da sua permeabilidade, o que pode ser observado pela menor condutividade hidráulica do solo nas parcelas em Cambissolo e LVAd sob pastagem nas condições atuais (Quadro 1).

Pérez-Rodriguez et al. (2007) mapearam o fator erodibilidade da EUPS para solos da região de Madrid, Espanha, e verificaram bom desempenho da krigagem, gerando mapas com boa precisão; salientase que tais mapas permitem analisar o fenômeno mapeado numa transição gradual dos valores, identificando-se áreas com maior propensão à erosão. Essa situação é relevante, uma vez que, em termos práticos, permite a adoção de técnicas mais apropriadas, tanto do ponto de vista técnico quanto econômico, para os diferentes ambientes dentro de uma bacia hidrográfica.
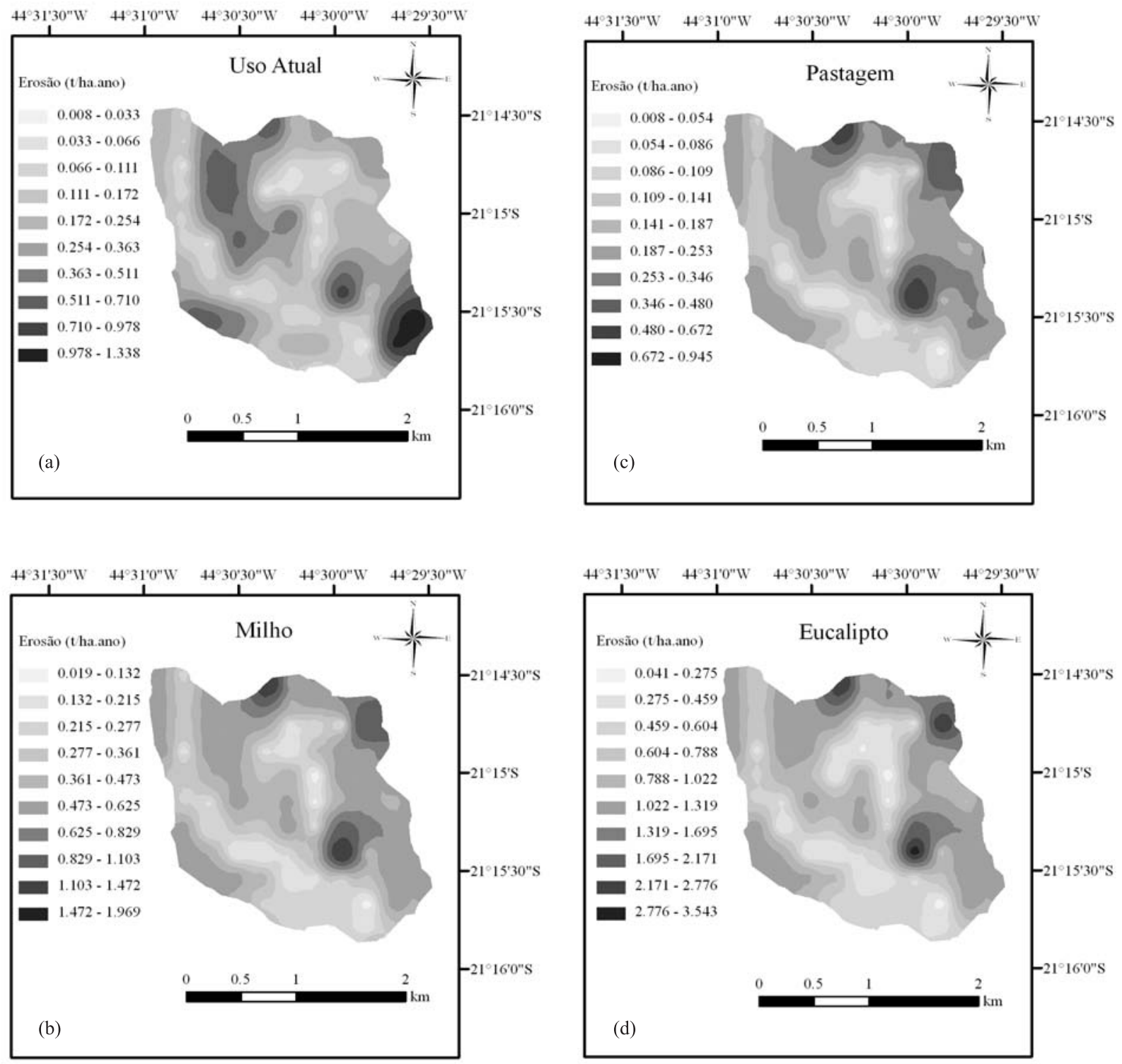

Figura 3. Simulação da distribuição espacial da erosão do solo, em t ha ${ }^{-1}$ ano $^{-1}$, para os cenários trabalhados na sub-bacia hidrográfica do Ribeirão Marcela. 
Wang et al. (2003), mapeando a erosão do solo com base na geoestatística, demonstraram que a krigagem teve desempenho significativamente melhor do que outros métodos de espacialização, reduzindo, de forma importante, as incertezas quanto à predição em locais não amostrados. Além disso, esses autores mencionam, da mesma forma que Pérez-Rodriguez et al. (2007), a boa estratificação espacial do processo erosivo e a importância dessa ferramenta para tomadas de decisão relativas à implantação de técnicas de controle da erosão de acordo com cada ambiente da bacia hidrográfica, bem como o manejo de forma mais adequada do uso do solo.

Uma aplicação adicional desses mapas consiste na orientação para implantação de técnicas para controle do processo erosivo na bacia hidrográfica. Locais com maior propensão à erosão, como Cambissolos com pastagem nativa, podem receber tratamento diferenciado, como implantação de terraços em gradiente, juntamente com técnicas de adubação simples, que permitam melhor desenvolvimento da cobertura vegetal, contribuindo para maior proteção do solo contra impacto de gotas e melhor interceptação do escoamento. Nas áreas de Latossolo com eucalipto seria interessante introduzir alguma gramínea que possa proteger o solo, como braquiária, e, a partir da remoção do eucalipto, recuperar o solo com alguma leguminosa. Essas são algumas recomendações cuja aplicação pode ser racionalizada, seguindo a distribuição espacial da erosão por meio dos mapas produzidos.

Segundo Araújo (2006), a sub-bacia hidrográfica em questão é representativa dos Latossolos na região do Alto Rio Grande, tendo, portanto, aptidão agrícola especialmente voltada a culturas anuais, como o milho - cultura tradicional do Sul de Minas. O cenário de ocupação do solo na sub-bacia com milho, considerando a prática conservacionista mais simples (plantio em nível), é uma situação factível. Na figura 3b pode ser analisada a distribuição espacial da erosão na subbacia hidrográfica tendo-se esse cenário como referência. Verifica-se aumento das perdas de solo em relação ao cenário atual sem, no entanto, superar a situação de uso do solo por eucalipto. De forma semelhante ao eucalipto, verificam-se regiões da subbacia com valores de perdas acima de $2,5 \mathrm{t} \mathrm{ha}^{-1} \mathrm{ano}^{-1}$ para as faixas com Cambissolos. Mesmo no LVAd, observam-se áreas com tendência de aumento da erosão. A sub-bacia hidrográfica, mediante esse cenário de uso, pode apresentar situações preocupantes quanto à erosão, mostrando necessidade de cuidados adicionais no manejo do solo. Comparando os resultados da simulação com aqueles das parcelas de monitoramento da erosão instaladas em Latossolo Vermelho e Cambissolo da região, conforme Silva et al. (2005), foi constatada perda anual de $14 \mathrm{t} \mathrm{ha}^{-1} \mathrm{ano}^{-1}$ para o Latossolo e de $200 \mathrm{t} \mathrm{ha}^{-1} \mathrm{ano}^{-1}$ para o Cambissolo, valores muito superiores aos simulados. A diferença de resultados deve-se a três fatores: as parcelas não possuem cobertura vegetal (solo descoberto), tem declividade consideravelmente superior (12\% para o Latossolo e $15 \%$ para o Cambissolo) à deste trabalho (valor máximo de $10 \%$ para o Latossolo e $12 \%$ para o Cambissolo) e a erosividade do período de monitoramento foi de aproximadamente $9.000 \mathrm{MJ} \mathrm{mm} \mathrm{ha}{ }^{-1} \mathrm{~h}^{-1} \mathrm{ano}^{-1}$. Observam-se, portanto, diferenças consideráveis, mas que, proporcionalmente, mostram que os resultados simulados são compatíveis com os observados.

Pandey et al. (2007), trabalhando com mapeamento da erosão com a EUPS por meio de SIG, com o objetivo de evidenciar áreas críticas quanto à erosão em uma bacia hidrográfica agrícola na Índia, comentam sobre a importância de ferramentas para mapeamento da erosão com base neste modelo, tendo encontrado resultados promissores quanto à aplicação prática deles no manejo e na conservação dos solos naquela condição. Nesse contexto, é possível verificar que a porção leste da sub-bacia apresenta tendência de geração de impacto negativo do uso do solo, com provável aumento da geração e produção de sedimentos, especialmente se este estiver concentrado em eucalipto mal manejado (área degradada), sem critérios conservacionistas de manejo, e cultivo de milho convencional. Esse setor da sub-bacia é fisiograficamente caracterizado por Cambissolo e Latossolo Vermelho-Amarelo, com declividade variando de 10 a $15 \%$, com menor taxa de infiltração de água no solo (Quadro 1). Com as simulações realizadas, foi possível perceber que essas áreas podem se tornar críticas, especialmente as de Cambissolos, e precisam ser adequadamente manejadas se houver implantação de culturas de ciclo curto e plantio de eucalipto nos moldes atuais.

É importante ressaltar que as simulações foram feitas com base num valor médio anual de erosividade da ordem de 8.030 MJ mm ha-1 $\mathrm{h}^{-1} \mathrm{ano}^{-1}$. De acordo com o relatório do IPCC sobre aquecimento global e seus impactos (Stott, 2007), um dos efeitos das mudanças climáticas que podem afetar o Sudeste do Brasil está associado à concentração cada vez maior das chuvas, havendo maior tendência à ocorrência de eventos extremos de precipitação pluvial intensa, produzindo chuvas com poder erosivo crescente. Este cenário, de provável maior erosividade das chuvas, também poderá ser simulado, mostrando a relevância do método proposto e dos resultados para avaliação e proposição de técnicas de manejo e conservação de água e solo a serem implementadas na região num futuro próximo. As técnicas de simulação têm se mostrado essenciais para o subsídio técnico-científico dessa abordagem.

\section{CONCLUSÕES}

1. O uso da EUPS associada a técnicas de espacialização da geoestatística revelou-se uma ferramenta de boa qualidade e aplicabilidade para 
simulação e mapeamento da erosão hídrica em escala de bacias hidrográficas, podendo ser promissora para estudos associados à conservação de água e solo, com identificação de setores da sub-bacia com maior potencial erosivo e, por conseqüência, de técnicas conservacionistas mais adequadas.

2. Tendo em vista os cenários simulados, avaliase que atualmente a sub-bacia hidrográfica não apresenta elevada taxa de erosão, com exceção das áreas ocupadas por eucalipto e pastagem em Cambissolos. Observou-se que existem áreas críticas no tocante à erosão especialmente se a sub-bacia for submetida à ocupação por eucalipto na forma tradicional de exploração na região, verificando-se taxas de erosão que podem superar os limites de tolerância de perdas, especialmente no Cambissolo.

3. Em todas as situações simuladas, foi possível constatar que o lado leste da sub-bacia apresenta as maiores taxas de erosão, sendo o setor mais alterado e que necessita de maiores cuidados no tocante ao manejo e conservação de água e solo, sobretudo se utilizado com eucalipto e plantio convencional de milho no Cambissolo e no LVAd.

\section{LITERATURA CITADA}

ARAÚJO, A.R. Solos da bacia do Alto Rio Grande (MG): Base para estudos hidrológicos e aptidão agrícola. Lavras, Universidade Federal de Lavras, 2006. 345p. (Tese de Doutorado)

BECERRA-SORIANO，R. \& GUTIÉRREZ-LOPEZ, A. Modelación hidrológica empleando isoyetas de relieve, uma aproximación geoestadística. In: DEMUTH, S.; GUSTARD, A.; PLANOS, E.; SCATENA, F. \& SERVAT, E. Climate variability and change - hydrological impacts. Wallingford, IAHS Press, 2006. p.62-67.

CAMBARDELLA, C.A.; MOORMAN, T.B.; NOVAK, J.M.; PARKIN, T.B.; KERLEN, D.L.; TURCO, R.F. \& KONOPKA, A.E. Field scale variability of soil properties in Central Iowa soils. Soil Sci. Soc. Am. J., 58:1501-1511, 1994.

DIGGLE, P.J. \& RIBEIRO JÚNIOR, P.J. Model-based geostatistics. New York, Springer Series in Statistics, 2007. 228p.

FISTIKOGLU, O. \& HARMANCIOGU, N.B. Integration of GIS with USLE in assessment of soil erosion. Water Res. Manag., 16:447-467, 2002.

IRVEN, A.; TOPALOGLU, F. \& UYGUR, V. Estimating spatial distribution of soil loss over Seyhan River Basin in Turkey. J. Hydrol., 336:30-37, 2007.

ISAAKS, E.H. \& SRIVASTAVA, R.M. Applied geoestatistic: An introduction to. New York, Oxford University Press, 1989. 561p.

LIMA, J.M.; CURI, N.; RESENDE, M. \& SANTANA, D.P. Dispersão do material de solo em água para avaliação indireta da erodibilidade de Latossolos. R. Bras. Ci. Solo, 14:85-90, 1990 .
MELLO, C.R.; LIMA, J.M.; SILVA, A.M.; MELLO, J.M. \& OLIVEIRA, M.S. Krigagem e inverso do quadrado da distância para interpolação dos parâmetros da equação de chuvas intensas. R. Bras. Ci. Solo, 27:925-933, 2003.

MELLO, C.R.; SÁ, M.A.C.; CURI, N.; MELLO, J.M. \& VIOLA, M.R. Erosividade mensal e anual da chuva no Estado de Minas Gerais. Pesq. Agropec. Bras., 42:537-545, 2007.

MELLO, J.M. Geoestatística aplicada ao inventário florestal. Piracicaba, Escola Superior de Agricultura Luiz de Queiroz, 2004. 110p. (Tese de Doutorado)

ONYANDO, J.O.; KISOYAN, P. \& CHEMELIL, M.C. Estimation of potential soil erosion for river Perkerra catchment in Kenya. Water Res. Manag., 19:133-146, 2005.

PANDEY, A.; CHOWDARY, V.M. \& MAL, B.C. Identification of critical erosion prone areas in the small agricultural watershed using USLE, GIS and remote sensing. Water Res. Manag., 21:729-746, 2007.

PÉREZ-RODRIGUEZ, R.; MARQUES, M.J. \& BIENES, R. Spatial variability of the soil erodibility parameters and their relation with the soil map at subgroup level. Sci. Total Environ., 378:166-173, 2007.

PROCHNOW, D.; DECHEN, S.C.F.; DE MARIA, I.C.; CASTRO, O.M. \& VIEIRA, S.R. Razão de perdas de terra e fator C da cultura do cafeeiro em cinco espaçamentos, em Pindorama (SP). R. Bras. Ci. Solo, 29:91-98, 2005.

RANIERI, S.B.L.; JONG VAN LIER, Q.; SPAROVEK, G. \& FLANAGAN, D.C. Erosion database interface (EDI): A computer program for georeferenced application of erosion prediction models. Comp. Geosci., 28:661-668, 2002.

RIBEIRO JÚNIOR, P.J. \& DIGGLE, P.P. GeoR: A package for geostatistical analysis. R. News, 1:15-18, 2001.

SILVA, A.C. Relação entre voçorocas e solos na região de Lavras (MG). Lavras, Universidade Federal de Lavras, 1990. 124p. (Tese de Mestrado)

SILVA, A.M.; SILVA, M.L.N.; CURI, N. \& LIMA, J.M. Perdas de solo, água, nutrientes e carbono orgânico em Cambissolo e Latossolo sob chuva natural. Pesq. Agropec. Bras., 40:1223-1230, 2005.

SILVA, M.L.N. Erosividade da chuva e proposição de modelos para estimar a erodibilidade de Latossolos brasileiros. Lavras, Universidade Federal de Lavras, 1997. 154p. (Tese de Doutorado)

SOUZA, Z.M.; MARTINS FILHO, M.V.; MARQUES JÚNIOR, J. \& PEREIRA, G.T. Variabilidade espacial de fatores de erosão em Latossolo Vermelho eutroférrico sob cultivo de cana-de-açúcar. Eng. Agríc., 25:105-114, 2005.

SPAROVEK, G. \& Jong van LIER, Q. Definition of tolerable soil conservation values. R. Bras. Ci. Solo, 21:467-471, 1997.

STOTT, P. Causes of past climate change and projections of future changes in climate. Genebra, IPCC, 2007. 25p.

WISCHMEIER, W.H. \& SMITH, D.D. Predicting rainfall erosion losses: A guide to conservation planning. Washington, United States Department of Agricultura, 1978. 58p.

WANG, G.X.; GERTNER, G.; FANG, S.F. \& ANDERSON, A.B. Mapping multiple variables for predicting soil loss by geostatistical methods with TM images and a slope map. Photogram. Eng. Remote Sens., 69:889-898, 2003. 